\title{
Promotion of hygiene habits at school - An adaptation of a project from Classroom Learning to Distance Learning
}

\author{
Catarina Gouveia ${ }^{1}$, Eduarda Silva ${ }^{2}$, Ana Silva ${ }^{3}$, João Silva ${ }^{4}$, António Barbot ${ }^{5}$, Guilherme Sousa- \\ Rodrigues $^{6}$, Pedro Rodrigues ${ }^{7}$ \\ ${ }^{1}$ School of Education of the Polytechnic Institute of Porto, Orcid ID: 0000-0003-0213-5809 \\ ${ }^{2}$ School of Education of the Polytechnic Institute of Porto, Orcid ID: 0000-0002-4094-9101 \\ ${ }^{3}$ School of Education of the Polytechnic Institute of Porto, Orcid ID: 0000-0003-4720-824X \\ ${ }^{4}$ School of Education of the Polytechnic Institute of Porto, Orcid ID: 0000-0002-0220-116X \\ ${ }^{5}$ School of Education of the Polytechnic Institute of Porto, Orcid ID: 0000-0001-9915-1519 \\ ${ }^{6}$ Fonte da Moura Basic School, Orcid ID: 0000-0001-6291-9002 \\ ${ }^{7}$ School of Education of the Polytechnic Institute of Porto, Orcid ID: 0000-0001-8862-2805 \\ Email: catarinagouveia13@outlook.com,duda_ruby@hotmail.com,anacatcruzsilva@gmail.com, \\ jvcrs92@gmail.com,antoniobarbot@ese.ipp.pt,aomeuritmo@gmail.com,pedrorodrigues@ese.ipp.pt
}

\begin{abstract}
Due to the COVID-19 pandemic and the challenges it brought to the Portuguese education system, there was a need of adapting a research project to be carried out in a school environment. Prior to the conception of the project, a problem was identified in 12 first grade students: a lack of hygiene habits of the students' hands. Therefore, an opportunity to create a project was identified, being its main goal to improve students' hygiene habits, with a focus on hand washing. The project became even more relevant due to the COVID-19 pandemic and the urgent need of proper hand washing habits. Simultaneously, the research project also aimed at creating alerts and warnings at school, related to proper hand hygiene practices. For the data gathering, the main instruments used were an initial and final questionnaire to the students, an interview with the teacher in charge of the class, as well as observation records, based on the students' dialogues and productions. Therefore, this is a research project of a mixed nature (qualitative and quantitative). After implementing some activities which aimed at changing hand hygiene habits, students understood that hand washing for at least 20 seconds with water and soap, using the correct technique, prevented the appearance and spread of diseases, being visible a change in habits.
\end{abstract}

Key words: Hygiene, Hand washing, Distance learning

\section{Introduction}

During an observation made in a first-grade class, a problem related to the hygiene habits of the students was identified, more specifically concerning their hand hygiene habits. That said, the class teacher was interviewed in order to have deeper knowledge of the students' habits, as well as a questionnaire was filled by the children about their hygiene routines. Considering that a problem consists of a need verified in a context and that it does not enable for something to function as desirable (Lopes, Cravino, Cruz \& Barbot, 2017), a research problem was identified and formulated: a lack of hygiene habits of the students' hands. Since the students always showed interest in activities related to their reality and in practical activities, an opportunity was found to promote proper hygiene practices, with a focus on hand washing. Moreover, this project proved to be very pertinent since hygiene is, in fact, essential for the children's individual and collective health, and appropriate hygiene habits should be promoted from an early age, including at school (Couto, Cunha, Neto, \& Soares, 2012). In fact, "health literacy is considered (...) to be one of the pillars of health promotion and a critical determinant of health for people's empowerment" (World Health Organization, 2020b, p. 5). However, hygiene can include several aspects such as body hygiene, hair hygiene, food hygiene, oral hygiene, among others. We highlight the importance of hand hygiene, since this is the main way of transmitting germs and, therefore, of spreading diseases (Estêvão, 2015). In addition, hand hygiene has an impact not only on health through the transmission of diseases, but also on education, as "a fragile health does not only affect children physically, but cognitively, which impairs their school performance and learning, and at the same time many children are forced to leave school due to illness" (Rema, 2017, p. 5). It should also be noted that, although this research project began before the first case of COVID-19 was officially confirmed in Portugal, the pandemic reinforces the importance of hand washing, since it is one of the 
most effective actions to reduce the spread of the virus (World Health Organization, 2020c). Moreover, the students live in an environment of low socioeconomic level, which is known to have an adverse impact on hand hygiene habits. Therefore, "educational applications on hand hygiene are very important for preventing epidemics, which can affect the school population and which can spread in this risky population" (Ö̈ncü et al., 2019, p. 343). Since the need for adequate hand hygiene habits became even more emerging, and also considering the main problem identified among the class, the importance and pertinence of this study is evident.

The COVID-19 pandemic forced an emergency transition from classroom learning to distance learning, which happened before the project was implemented with the students, despite its goals and method being already stipulated. Considering this, the whole research project had to be adapted, taking into account the potentialities of emergency distance learning, as well as its disadvantages comparing to classroom learning. Since some of the activities planned to carry out with the students were not possible to do with this modality, the aims of the project were also adapted. Therefore, before the COVID-19 pandemic, the aims were to improve students' hygiene habits and create alerts and warnings at school, related to proper hand hygiene practices. In fact, Andrade (1995) refers that "health education implies a situation of change aimed at improving individual and collective health and, through multiple learning experiences, aims to change the health situation in the school community" (p. 22). However, during the COVID-19 pandemic, the second aim was adapted, becoming to contribute to the awareness of the need for better hygiene habits, through online sharing of resources created by students for the school community in general. Moreover, since the problem of the study is the lack of hygiene habits of the students' hands, some research questions were formulated, which also had to be adapted considering the transition to distance learning. Initially, the research questions were:

- Does an experimental work of a microbiological character that presupposes students' contact with the reality of their hand hygiene, allow them to improve their hygiene habits?

- Is it possible, together with the students, to develop resources or organize activities that promote improvements in a medium/long-term concerning hygiene habits at school?

However, due to the impossibility of doing the experimental work of microbiological character that aimed to put students in contact with the reality of their hand hygiene, as well as the impossibility of distributing resources and organizing activities at the school itself, these questions were adapted, becoming:

- Is it viable, in a distance learning reality, to develop activities that promote hygiene habits in students?

- Is it possible, together with the students, to develop resources or organize remote activities that contribute to good hygiene habits at school?

\section{Method}

The population of the research project is a first-grade class of 24 students aged between 6 and 7 years old, who attend a school in Porto inserted in a socially and economically deprived environment. However, since not all students had access to online classes due to the lack of internet access at home, the sample of the research are 12 students: four 6-year-old students and eight 7-year-old students, being half of the children females and the other half males. Due to the COVID-19 pandemic and the challenges it brought, there was also a need of adapting the research project's method and activities.

\section{Data collection tools}

Before the pandemic, the data collection tools and techniques planned were an initial and final interview with the teacher to sustain the problem initially identified and to verify if the teacher detected changes in the children's hygiene habits overtime, an initial and final students' questionnaire to conclude if their knowledge and habits concerning hand hygiene changed, observation, multimodal narratives and monitoring of students' hand hygiene through culture mediums. Concerning multimodal narratives, Lopes, Viegas and Pinto (2019) explain its concept, reminding that "multimodal" refers to the fact that "the reality in the classroom mobilizes a range of semiotic registers, verbal, gestural, graphical etc., at a given time; if you want to grasp the state of the interaction, you must collect data at these different planes" (p. 20), while "narrative" is linked to the fact that "the classroom activity is a story, coherent along time, with a history and an aim, and you cannot understand one moment of the story without knowing what happened before and what happened after" (p. 20). Due to the transition to distance learning, this tool could not be used as initially planned, as well as the culture mediums to monitor the students' hands at different times (before lunch, after lunch, at the end of the class, after using the restroom, among others). 
In order to collect data through remote learning, the tools and techniques became: an interview with the class teacher, an initial and final students' questionnaire, observation and the students' work and productions. According to Carmo and Ferreira (1998), the use of an interview during an investigation is recommended when "the investigator has relevant questions whose answer is not found in the available documentation or, having found it, it does not seem reliable, being necessary to prove it" (p. 128). Since the class teacher interacts with the students frequently, it became pertinent to conclude through the interview if the identified problem was verified in the classroom daily. Thus, it was intended to confirm whether the class teacher had already verified the gap in students' hand hygiene habits and whether the pandemic altered their hygiene routines in the classroom. Therefore, the interview was carried out through an online video call, considering the pandemic, and three questions were made to the class teacher, which were: "Do you consider that there is a problem of lack of hygiene habits in the class? Why?"; "The students went to school for a week after the first cases of Covid-19 were confirmed in Portugal. Were there changes in the class routine, regarding the students' hand hygiene habits? Which changes?"; and "Do you consider it possible and pertinent to carry out the activities of this research project, which aim to improve the hygiene habits of students, in a distance learning modality? What other activities would you do?". The answers collected to these questions will be later explored, in order to discuss the results of the project and draw some conclusions, considering the class teacher's perspective. Regarding the questionnaires to the students, these were implemented through an online platform before and after the activities carried out. The questions were created with the aim of knowing the students' hygiene habits, as well as their knowledge regarding the importance of good habits and the proper hand washing technique. These questions will be presented and discussed in the findings section. Moreover, since multimodal narratives would not be possible to make, observation gained and even greater importance for this research project. In fact, "observations enable the researcher to describe existing situations using the five senses, providing a "written photograph" of the situation under study" (Kawulich, 2005, p. 2). Observations of the online classes where the activities were implemented were carried out, as well as observations of the students' productions and work which were sent to the trainee teachers.

\section{Data analysis}

Since this research project uses both quantitative methods, through the students' questionnaires, and qualitative methods, through the interview with the class teacher, observation and the students' productions, this study uses a mixed method. According to Doyle, Brady and Byrne (2009), "the purpose of mixing approaches is to afford opportunity to gain a more complete understanding of research problems (...) [and it] offers greater possibilities than a single method approach for responding to decision makers agenda, as well as to the interests of other legitimate stakeholders" (p. 184). Therefore, this method proved to be adequate to understand the evolution of the students' knowledge about hand hygiene, as well as the change in their habits.

\section{Implementation steps}

Before the emergency distance learning, some activities were planned for classroom learning to explore the main subject of this project, in order to improve the students' hygiene habits. The intervention plan included 5 activities, in a logical and sequential manner:

1) Activity related to the importance of hand washing time, using paint.

2) Experimental work of microbiological character to compare hand washing with and without soap.

3) Hand washing technique (SureWash mobile app).

4) Monitoring of students' hands over time using culture mediums.

5) Building of posters and leaflets to distribute around the school.

The first aim was to implement an activity related to the importance of hand washing time, using paint. With their hands painted, the students would put them in a paper sheet. Afterwards, the same would be done but only after washing the hands for 5 seconds and, after, this process would be repeated with hands washed for 20 seconds. This way, the aim was to conclude that our hands should be washed during, at least, 20 seconds, being evident that hand washing time plays an important role in good hand hygiene. After knowing the correct amount of hand washing time, students should conclude the best way to do it, that is, with water and soap. Therefore, an experimental work of microbiological character to compare hand washing with and without soap, would be carried out, through culture mediums. The appropriate hand washing technique would also be explored using the Surewash mobile app. With this app, students could see, step by step, and train the correct hand washing technique through augmented reality. The children's hands would also be monitored overtime using culture mediums at different times of the day 
(before and after lunch, after using the restroom, at the end of the class) to conclude if there was any progress of their hygiene habits. After all the knowledge developed, it was intended to share it with the school community, by creating and distributing posters and leaflets around the school made by the children.

However, these activities had to be adapted for emergency remote learning, except for the first activity related to hand washing time using paint, which was possible to be done by the students at home. Therefore, the implementation steps were modified, becoming:

1) "Hand hygiene: different habits" video.

2) Activity related to the importance of hand washing time, using paint.

3) Observation of the best hand washing method, using bread as a culture medium.

4) Hand washing technique (SureWash mobile app).

5) Creation of a song and a music video about the importance of hand washing.

Before the paint activity, the students watched a video called "Hand hygiene: different habits" created by the trainee teachers, where they could see and identify good and bad hygiene habits. Instead of an experimental work of microbiological character using culture mediums, the observation of the best hand washing method was made using bread slices as a culture medium. This way, students were able to observe the growth of microorganisms in the pictures of bread slices touched in different ways: bread touched with dirty hands; bread touched by hands cleaned with water and soap; bread touched by hands cleaned with hand sanitizer; bread touched by hands cleaned with alcohol; bread rubbed in a computer keyboard. Therefore, through this activity, it was possible to also explore the presence of microorganisms in apparently clean surfaces. Furthermore, the students made a "True or False" game where some sentences previously included in the initial questionnaire were explored. The Surewash mobile app was also used at home by the students to learn and practice the different steps of the adequate hand washing technique. Videos and pictures of this activity were sent to the trainee teachers and were later used in the creation of a video to share with the community in general. However, prior to the creation of the video, a revising game created by the teachers called "Hand hygiene expert" was carried out to revise all the knowledge students developed concerning the main subject of the project. Lastly, since it was not possible to create and distribute leaflets and posters around the school itself, a song and a music video was created together with the students about the importance of hand washing, to share with the community through online platforms.

\section{Findings}

In this section of the paper, we intend to present and explore the results obtained through the questionnaires completed by the students. The initial questionnaire was filled by all 12 students, being the first question of the questionnaire "Do you think hand washing is important? Why?" to which all the students answered "yes". Concerning the reason why it is important, 7 of the students mentioned that we should wash our hands to make them clean and get rid of dirt. However, 3 students also referred to the presence of microorganisms as it is evident in the following answers: "Yes, because of microbes"; "Yes, because it is the only way of eliminating bacteria and viruses"; "Yes, due to microbes". The other 2 students considered the importance of hand washing to disease prevention, answering: "Yes, to avoid being sick"; "Yes, to make the hands cleaned and avoid diseases". Through these answers, it is possible to conclude that the students already had some knowledge about the importance of hand washing prior to the implementation of this project, although this can also be due to the COVID-19 pandemic and the constant information available concerning hand washing habits. Additionally, in the third question of the questionnaire, all the students mentioned they wash their hands with water and soap. Thus, it is visible that the children already knew that our hands should not be washed only with water or hand sanitizer, being the best method to use soap and water regularly.

Table 1. Answers by the students to the question: "How do you usually wash your hands?"

\begin{tabular}{cc}
\hline Variables & Frequency \\
\hline Only with water & -- \\
With water and soap & 12 \\
With hand sanitizer & -- \\
\hline
\end{tabular}


The fourth question aimed at the regularity of the students' hygiene habits at certain moments of the day. Of all the 12 students, only 8 mentioned they always wash their hands after using the restroom and before eating. One student even referred to never doing it, and the other respondents do it sometimes. It was also possible to conclude that the habit of hand washing after eating is not as frequent among these children, since only 4 confirmed they always do it, and, once again, one student admits to never wash the hands after a meal. The moments where almost every student (11 students) mentioned to always wash their hands were when they saw them with visible dirt and after playing with soil or sand, with only one respondent to do it very frequently, but not always. A more concerning aspect could be concluded through the fact that only one student always washes the hands after coughing, sneezing and blowing. The majority mentioned to do it regularly (8 students) and the rest of the children (3 students) admitted to only doing it at certain times. As to hand washing after playing with pets or after touching an open wound, less than half the children referred to always having these habits (5 students), with the rest of the students mentioning to do it sometimes.

Table 2. Hand washing regularity by the students in different situations

\begin{tabular}{ccccc}
\hline \multirow{2}{*}{ Variables } & \multicolumn{5}{c}{ Frequency } \\
\cline { 2 - 5 } & Never & Sometimes & Regularly & Always \\
\hline After using the restroom & 1 & 1 & 2 & 8 \\
Before eating & 1 & 1 & 2 & 8 \\
After eating & 1 & 3 & 4 & 4 \\
When hands are visibly dirty & -- & -- & 1 & 11 \\
After coughing, sneezing and & -- & 3 & 8 & 1 \\
blowing & -- & 4 & 3 & 5 \\
After playing with pets & -- & -- & 1 & 11 \\
After playing with soil or sand & -- & 2 & 4 & 6 \\
After touching an open wound & & &
\end{tabular}

Furthermore, through the fifth question it was possible to reinforce the idea of the need to promote good hand hygiene habits, since 4 students said they constantly needed to be told and reminded by a family member to wash their hands, not doing it autonomously. However, 11 students mentioned they always washed their hands by their own, with only one student needing the help of an adult.

Table 3. Sentences the students identify with, concerning their hand hygiene habits

\begin{tabular}{lc}
\hline Variables & Frequency \\
\hline $\begin{array}{l}\text { I wash my hands whenever I see an } \\
\text { adult washing too. }\end{array}$ & 3 \\
$\begin{array}{l}\text { I decide to wash my hands, without } \\
\text { anyone having to ask me. } \\
\text { I often need an adult to warn me to } \\
\quad \text { wash my hands. }\end{array}$ & 8 \\
$\quad \begin{array}{l}\text { I wash my hands by my own. } \\
\text { I usually ask an adult for help to } \\
\text { wash my hands. }\end{array}$ & 11 \\
\hline
\end{tabular}

Lastly, some sentences were exposed in the final question, where the children should conclude if they were true or false, according to their knowledge. All students showed they knew that we should wash our hands not only when they are visibly dirty and that the hands should be well dried after washing. However, the other sentences resulted in different answers, such as "It is always necessary to use hand sanitizer to ensure our hands are cleaned". In fact, 3 students answered "True", although it is false due to the efficacy of proper hand washing with water and soap, being this the most recommended method. 
Moreover, one student answered "True" to the sentence "Hand washing for 10 seconds is enough", which shows the lack of knowledge concerning the right amount of hand washing time (at least 20 seconds).

Table 4. Answers by the students to the question: "Read the sentences and select if they are true or false"

\begin{tabular}{|c|c|c|}
\hline \multirow{2}{*}{ Variables } & \multicolumn{2}{|c|}{ Frequency } \\
\hline & True & False \\
\hline $\begin{array}{l}\text { We should only wash our hands when } \\
\text { they are visibly dirty. }\end{array}$ & -- & 12 \\
\hline $\begin{array}{l}\text { It is always necessary to use hand } \\
\text { sanitizer to ensure our hands are cleaned. }\end{array}$ & 3 & 9 \\
\hline $\begin{array}{l}\text { After hand washing, it is very important } \\
\text { to dry them well. }\end{array}$ & 12 & -- \\
\hline Hand washing for 10 seconds is enough. & 1 & 11 \\
\hline $\begin{array}{l}\text { Hand washing time is more important } \\
\text { than hand washing technique. }\end{array}$ & 1 & 11 \\
\hline $\begin{array}{l}\text { Hand washing several times a day } \\
\text { reduces the risk of having some illnesses. }\end{array}$ & 11 & 1 \\
\hline
\end{tabular}

This questionnaire was answered by the students before the activities planned were implemented, being the main goal to collect their knowledge concerning basic aspects related to hand washing and its importance. These aspects were later explored, including the sentences of the "True or False" section, to demystify some myths and increase the knowledge the students already demonstrated. After the activities were implemented, the children answered a final questionnaire with some of the same questions as the initial one, so the answers could be compared. However, and due to some difficulties intrinsic to distance learning and the fact that the school year was about to finish, only 5 students answered the questionnaire. Therefore, although we can take some conclusions, these cannot be considered as fully reliable since the questionnaires were of anonymous character, making it impossible to know which students answered both the questionnaires to compare their answers. Nevertheless, it should be noted that concerning the regularity of hand washing at certain times of the day, significant improvements were visible with all students saying they always wash their hands after eating, when they see they are visibly dirty, after coughing, sneezing and blowing and after playing with soil and sand. Also, no student mentioned to never wash their hands in the moments of the day exposed, although some admitted to still not always do it after going to the bathroom ( 2 students), before eating ( 3 students), after playing with pets ( 3 students) and after touching an open wound (2 students).

Table 5. Hand washing regularity by the students in different situations (after the implemented activities)

\begin{tabular}{ccccc}
\hline Variables & \multicolumn{4}{c}{ Frequency } \\
\cline { 2 - 5 } & Never & Sometimes & Regularly & Always \\
\hline After using the restroom & -- & 1 & 1 & 3 \\
Before eating & -- & 1 & 2 & 2 \\
After eating & -- & -- & -- & 5 \\
When hands are visibly dirty & -- & -- & -- & 5 \\
After coughing, sneezing and & -- & -- & 1 & 4 \\
blowing & -- & -- & 3 & 2 \\
After playing with pets & -- & -- & -- & 5 \\
After playing with soil or sand & -- & 1 & 1 & 3 \\
After touching an open wound & & &
\end{tabular}


Lastly, considering the "True or False" sentences, the answers were significantly more homogeneous. In fact, only one sentence still caused discord: "It is always necessary to use hand sanitizer to ensure our hands are cleaned", with one student considering this to be true.

Table 6. Answers by the students to the question: "Read the sentences and select if they are true or false", after the implemented activities

\begin{tabular}{|c|c|c|}
\hline \multirow{2}{*}{ Variables } & \multicolumn{2}{|c|}{ Frequency } \\
\hline & True & False \\
\hline $\begin{array}{l}\text { We should only wash our hands when } \\
\text { they are visibly dirty. }\end{array}$ & -- & 5 \\
\hline $\begin{array}{l}\text { It is always necessary to use hand } \\
\text { sanitizer to ensure our hands are cleaned. }\end{array}$ & 1 & 4 \\
\hline $\begin{array}{l}\text { After hand washing, it is very important } \\
\text { to dry them well. }\end{array}$ & 5 & -- \\
\hline Hand washing for 10 seconds is enough. & -- & 5 \\
\hline $\begin{array}{l}\text { Hand washing time is more important } \\
\text { than hand washing technique. }\end{array}$ & -- & 5 \\
\hline $\begin{array}{l}\text { Hand washing several times a day } \\
\text { reduces the risk of having some illnesses. }\end{array}$ & 5 & -- \\
\hline
\end{tabular}

\section{Results and Discussion}

Since the method of the project is exposed, the presentation of the results obtained during this investigation follows, as well as its analysis, resulting afterwards in the conclusions drawn from this project and the suggestions for future improvement.

\section{Results}

During the teaching and learning process of the students who participated in the study, it was possible to verify knowledge acquired by the students and even a change in some of their habits. The first major aspect to highlight refers to the first activity carried out with the children: the viewing of a video entitled "Hand hygiene: different habits". Here, the students identified the existence of two different behaviors regarding hand hygiene habits of two characters, immediately concluding the erroneous aspects. Such aspects were focused on the different moments of hand washing, emphasizing that it should be done before and after eating, after going to the bathroom or playing moments and whenever the hands are visibly dirty. In addition, at this moment, some students transposed these habits to their own behaviors, and it was evident that they did not always wash their hands with the adequate regularity, namely after eating or using the bathroom. However, this principle of awareness was detected, which, as the National Association for Infection Control (2015) says, it is important to encourage children to wash their hands at the right times, as it will ensure that such hygiene practices are reflected in a habit for life. Furthermore, according to the World Health Organization (2020a), schools should promote "hand hygiene behaviour change approaches in the curriculum to promote hand hygiene among children and their families and wider communities at critical times (before and after using the bathroom, before meals, and after outdoor play)" (p. 6).

In this short video, which set the tone for the entire didactic sequence carried out in this distance learning modality, the topic of the ideal time for hand washing was also focused which, once questioned to the students, they recognized that one of the characters in the video performed hand washing quickly and improperly. With the practical experimental activity using paint, which emphasized whether the time variable interfered with hand cleaning, all students were able to quickly understand that to obtain good hygiene of this part of the body it was necessary to wash it for at least 20 seconds. Nevertheless, the predictions made by the students should be noted. They made an audio recording where they expressed their predictions about what the activity was going to be and the conclusions they could reach. In these 
recordings, it was already evident the importance that students gave to hand hygiene and the inherent consequences of poor hygiene for health, demonstrating previous knowledge, in part as a result from the pandemic situation experienced in 2020. Thus, a 7-year-old student said: "The time [of hand washing] is very important because if we do it for 5 seconds it is not enough and they [the hands] may still be dirty. If we do it for 20 seconds, they are already better washed". Similarly, another participant mentioned: "They are better washed in 20 seconds, because we have more time to wash our hands and remove the microbes". Another student, of the same age group, went further and said: "We have to wash our hands very well to eliminate viruses and bacteria, otherwise we will get sick and we may have to stay home with the flu, with colds... . And we have to stay at home in quarantine because of COVID-19 and illnesses. If we do not want to go to the hospital, we have to wash our hands and rub them with hand sanitizer." In fact, it is recognized that one of the most effective methods of disease prevention is proper hand hygiene and "WHO (2009) points it out as one of the measures that has the most impact on reducing infections" (Couto, Cunha, Neto \& Soares, 2012, p.17), having a great impact on our individual and collective health, being the hands a great source of germ transmission (National Association for Infection Control - ANCI, 2015). On the other hand, when children start to interpret the benefits of habits for their health, it is when they are most motivated and will put them into practice with due regularity (Couto et al., 2012).

The students, during the learning process, were visibly referring that, based on the observation of the slices of bread, hands washed with water and soap were the ideal way to keep them cleaner and free of microbes compared to other means. This activity was in fact very visible for the children, who were surprised by the amount of mold present in the bread that was rubbed on the computer keyboard. This aspect was highlighted so that students understood that surfaces are a good way of transmitting microorganisms to their hands and, although apparently clean, it is necessary to clean them frequently. The "True or false?" activity allowed not only to understand if the children understood all these topics explored about hand washing, but also to compare with statements included in the initial questionnaire. In fact, it was clear that all students understood and got the value of the statements right, improving the data collected by the questionnaire. There were visible improvements in knowledge regarding hygiene habits and some awareness for this subject. Likewise, in the game activity "Expert in Hand Hygiene", all participants demonstrated knowledge, learning a new word - "microorganism" -, which for most children was unknown.

Regarding the hand washing technique, although some students already mentioned that they knew it due to the pandemic, it was necessary to practice it. This practice was carried out both by the app for mobile devices and by the creation of the music video, where they showed how to wash their hands properly through short videos, pictures and drawings. In another study, researchers concluded that "strong visual learner students may develop effective handwashing techniques when visually stimulated" (Öncü et al., 2019, p. 343). The Surewash mobile app allowed students to observe and reproduce the different steps of the adequate handwashing technique, being present the visual effect. Moreover, another research project (Rema, 2017) with a focus on promotion of good hand hygiene habits, showed that "carrying out practical science activities contributes to progress in the acquisition of hygiene habits and to begin to understand the importance of handwashing" (p. 35). In fact, at the end of the project, when the students were asked about what they learned, they referred to aspects such as:

- "I learned a lot about hand washing." (student, 7 years old);

- "We should wash our hands very well with water and soap." (student, 7 years old);

- " "It is very, very important to wash our hands." (student, 7 years old);

- $\quad$ "[We should wash our hands often] to remove germs." (student, 7 years old);

- " "If we don't use the adequate hand washing technique, it's not worth washing for 20 seconds." (student, 7 years old).

\section{Discussion}

Taking into account the mentioned aspects, as well as the aims and research questions outlined, it can be concluded that the students demonstrated various knowledge about this theme, more specifically about the importance of hand washing, the consequences of this for individual and collective health and the most effective way to do it, that is, with soap and water. Throughout this research project, the students revealed that they did not have knowledge about the proper time for hand washing, although one of the students was aware that it should not be too fast, as we can conclude by his statement: "I sing the Happy Birthday song while washing my hands". Another aspect the students did not acknowledge before was the presence of microorganisms on apparently clean surfaces. All of these aspects contributed to make students aware of hand hygiene, which, therefore, may have contributed to an increase in hand hygiene habits. 
In fact, the aims of the project were met, especially the aim related to the share of the aspects learned with the community, contributing to a greater awareness of the importance of proper hand washing habits. The song, created together by the students and the trainee teachers, and its music video was shared on the internet, namely on YouTube and social networks. The aim 'to improve students' hygiene habits" can be considered partially achieved. Considering the current pandemic of COVID-19, students demonstrated greater awareness of the importance of hand hygiene for the health of our body. This research project started with the identification of the problem before the pandemic and, when the intervention was carried out with the students, their hygiene habits were already significantly better. This was due to the students' concern to keep hand sanitizer nearby to disinfect their hands during the last classroom classes, or to the habits developed during two weeks, in the beginning of COVID-19 in the Portuguese territory, since the class teacher asked the children to wash their hands when entering and leaving the classroom systematically. All of these aspects contributed to the research results being noticeably more evident.

\section{Conclusions and Recommendations}

Regarding the research questions - "Is it viable, in a distance learning reality, to develop activities that promote hygiene habits in students?"; "Is it possible, together with the students, to develop resources or organize remote activities that contribute to good hygiene habits at school?", the answers to them are affirmative. Evidently, in an emergency distance learning modality, there are certain strategies whose implementation is complex and impossible, namely those related to microbiological activities that require observation with a microscope and other materials that are not available in the students' family environment. As such, it is necessary to have adequacy and adaptation both to the teaching modality and to the real context of the children, which in this case, is already economically and socially unfavourable. However, it was possible to carry out a meaningful learning path, where awareness, dialogue and promotion of practices were carried out.

One of the major disadvantages of emergency distance learning imposed by the pandemic was the difficulty of monitoring children's hygiene habits over time. In this modality, the monitoring was limited to the analysis of videos, images and questionnaires answered by the children and their families, resulting in an indirect analysis. In a classroom context, there would be a direct and systematic observation of the students and their habits, which would allow us to state that the activities developed were transformed into knowledge that, in turn, would be translated into good hygiene habits. As Couto et al. (2012) refers, "educating for health and hygiene, in a contextualized and systematic way, becomes a great challenge for education, regarding the possibility of ensuring effective and transformative learning." (p. 15). As such, this education must be permanent over time, involving a lot of observation of the habits of the children, for there to be an effective change. As a matter of fact, as the professor in charge of the class also explained during the interview, habits take time and require permanent practice. He also added that, under these conditions of implementation, the evaluation is limiting, and the results can only be reliable in the next school year by observation and initial diagnosis, since there are several variables to interfere. Furthermore, it is a habit that requires insistence on time, until it is assimilated and there is an evident degree of autonomy in students. That said, for future improvements it is advisable to ensure better monitoring of the habits of the students over time, to collect more evidence of learning and, therefore, to be able to state that the proposed main aim - to improve the students' hand hygiene - was fulfilled.

\section{Acknowkledgement}

This work is financially supported by National Funds through FCT - Fundação para a Ciência e a Tecnologia, I.P. under the project UIDB/00194/2020.

\section{References}

Andrade, M. I. (1995). Educação para a saúde: guia para professores e educadores. Lisboa: Texto Editora.

Carmo, H., \& Ferreira, M. M. (1998). Metodologia da investigação: guia para auto-aprendizagem. Lisboa: Universidade Aberta.

Couto, I., Cunha, S., Neto, S., \& Soares, M. (2012). Hábitos de higiene corporal e higienização das mãos - Um projeto de intervenção em contexto escolar. Internship report. Polytechnic Health Institute of North, Vale do Sousa, Portugal.

Doyle, L., Brady, A., Byrne, G. (2009). An overview of mixed methods research. Journal of Research in Nursing,

14

175-185

Available

at: https://journals.sagepub.com/doi/abs/10.1177/1744987108093962 
Estêvão, M. (2015). Higienização das Mãos: Uma Precaução Básica na Prevenção da Infeção. Project report. Polytechnic Institute of Setúbal, Setúbal, Portugal.

Kawulich, B. B. (2005). Participant Observation as a Data Collection Method. Forum: Qualitative Sozialforschung/Forum: Qualitative Social Research [On-line Journal], 6(2), Art. 43. Available at: http://www.qualitative-research.net/fqs-texte/2-05/05-2-43-e.htm.

Lopes, J. B., Cravino, J., Cruz, E., \& Barbot, A. (2017). Teaching Science: Contributions of Research for Planning, Practice and Professional Development. ed. 1, ISBN: 978-1-53612381-4. New York: Nova Science.

Lopes, J. B., Viegas, M. C., \& Pinto, J. A. (2019). Multimodal Narratives in Research and Teaching Practices. Hershey: IGI Global.

National Association for Infection Control (2015). Higiene das Mãos. Available at: http://www.anci.pt/higiene-das-m\%C3\%A3os

Öncü, E., Vayısoğlu, S., Lafci, D., Yurtsever, D., Bulut, E., \& Peker, E. (2019). Comparison of Interactive Education Versus Fluorescent Concretization on Hand Hygiene Compliance Among Primary School Students: A Randomized Controlled Trial. The Journal of School Nursing, 35(5), 337-347. https://doi.org/10.1177/1059840518785447

Rema, D. (2017). Vamos lavar as mãos! Um Estudo sobre a Aquisição de Hábitos de Higiene em Creche. Dissertação de mestrado. Instituto Superior de Educação e Ciências, Lisboa, Portugal.

World Health Organization. (2020a). Hand hygiene for all. Available at: https://www.unicef.org/media/71776/file/Hand-hygiene-for-all-2020.pdf.

World Health Organization. (2020b). Life skills education school handbook: prevention of noncommunicable diseases - Introduction. Geneva. Licence: CC BY-NC-SA 3.0 IGO. Available at: https://www.who.int/publications/i/item/9789240005020.

World Health Organization. (2020c). Who save lives: clean your hands in the context of Covid-19. Available at: https://www.who.int/infection-prevention/campaigns/clean-hands/WHO_HH-CommunityCampaign_finalv3.pdf?fbclid=IwAR3PGCbYZtdPDIP7cD1vPccl1oF1zbgYOpilynOUQPJGtXMvnSMltVY750. 